\title{
Combate à pandemia de covid-19 e sucesso eleitoral nas capitais brasileiras em 2020
}

\author{
Vítor Eduardo Veras de Sandes-Freitas ${ }^{1,2}$ \\ Helga do Nascimento de Almeida ${ }^{3,4}$ \\ Thiago Rodrigues Silame ${ }^{5}$ \\ Luciana Santana ${ }^{6,7}$
}

DOI: $10.1590 / 0103-3352.2021 .36 .246974$

\section{Introdução}

A pandemia da covid-19, doença causada pelo vírus SARS-CoV-2, ocasionou diversos impactos em todo o mundo. A rápida expansão territorial do vírus e a evolução do número de casos e óbitos colocou à prova a capacidade de respostas dos governos em todas as esferas, com o objetivo de minimizar os diversos efeitos da doença. Além da gravidade da doença em si, outros fatores potencializaram a situação no caso do Brasil, tais como a ausência de liderança nacional e a descoordenação federativa. Se por um lado, a inação presidencial se expressou nos mais variados comportamentos e atitudes anticientificistas e negacionistas que, além de prejudicar as ações locais, geraram insegurança e incerteza na população quanto à necessidade de adesão às medidas, por outro lado, os governos subnacionais tiveram de buscar estratégias e adotar medidas diversas para o enfrentamento da doença.

1 Para replicação dos dados ver: https://doi.org/10.7910/DVN/MQOYUL

2 Professor Adjunto da Universidade Federal do Piauí (UFPI), Centro de Ciências Humanas e Letras, Coordenação de Ciência Política, Teresina, PI, Brasil.E-mail: vitorsandes@ufpi.edu.br

3 Professora Adjunta da Universidade Federal do Vale do São Francisco (UNIVASF), Colegiado de Ciências Sociais, Juazeiro, BA, Brasil. E-mail: helgaalmeida@gmail.com

4 Professora da Universidade Federal do Piauí (UFPI), Programa de Pós-Graduação em Ciência Política, Teresina, PI, Brasil.

5 Professor Adjunto da Universidade Federal de Alfenas (UNIFAL), Instituto de Ciências Humanas e Letras, Alfenas, MG, Brasil. E-mail: thiago.silame@unifal-mg.edu.br

6 Professora Adjunta da Universidade Federal de Alagoas (UFAL), Instituto de Ciências Sociais, Maceió, AL, Brasil. E-mail: lucianacfsantana@yahoo.com.br

7 Professora da Universidade Federal do Piauí (UFPI), Programa de Pós-Graduação em Ciência Política, Teresina, PI, Brasil. 
Foi em meio a essa crise sanitária que ocorreram no Brasil eleições municipais para a escolha de prefeitos e vereadores. Com seu calendário alterado, as eleições foram marcadas, na sua dimensão procedimental, pela adoção de protocolos de distanciamento social e de higiene pessoal para evitar o contágio da doença durante o processo eleitoral. Já na sua dimensão formal, viu-se a entrada em vigor de legislação que proibiu as coligações para os cargos proporcionais, o que ocasionou o aumento de candidaturas para as prefeituras com o objetivo de alavancar a votação de candidatos a vereador.

Considerando o contexto de pandemia de covid-19, assumimos, neste artigo, que a agenda de enfrentamento à pandemia adotada por prefeitos tem impactos diversos sobre os resultados eleitorais, sobretudo se considerarmos que as medidas adotadas pelas prefeituras são aquelas percebidas de forma mais tangível pelos cidadãos (ROCHA; KERBAUY, 2014).

Isso posto, a presente análise visa verificar se a forma como os prefeitos de capitais lidaram com a crise sanitária impactou em seu sucesso eleitoral. Nesse sentido, é possível identificar variáveis políticas e contextuais que explicam o sucesso eleitoral dos prefeitos (ou de seus candidatos) das capitais brasileiras?

Para responder a essa questão, recorremos, como estratégia de análise, ao método Qualitative Comparative Analysis (QCA). Analisamos os resultados das eleições municipais em 25 capitais $^{8}$. Assumimos como sucesso a situação em que prefeitos lograram êxito em se reeleger ou que conseguiram eleger o sucessor. Nosso modelo mobiliza quatro condições causais. A primeira condição diz respeito à aprovação do prefeito. A segunda refere-se ao grau de rigidez das medidas adotadas nas capitais. Para isso, utilizamos um índice construído pelo Instituto de Pesquisa Econômica Aplicada (Ipea). A terceira condição causal observada é a taxa de óbitos ocasionados pela covid-19 por 100 mil habitantes. Por fim, consideramos como última condição causal o alinhamento de prefeitos das capitais em relação ao governo federal.

Nossa hipótese é a de que a configuração causal, que reúne prefeitos aprovados pela população, os quais adotaram medidas rigorosas de isolamento

8 Em 2020, as eleições municipais ocorreram no dia 15 de novembro. Entretanto, o pleito não aconteceu na cidade de Macapá, capital do estado do Amapá, em função de uma crise energética que deixou o estado vários dias sem energia, o que comprometeu a realização da eleição na cidade. Assim sendo, a eleição prevista para o dia 15 de novembro ocorreu no dia 06 de dezembro e não foi definida no primeiro turno. O segundo turno transcorreu no dia 20 de dezembro. 
e distanciamento social, que não se alinharam ao presidente da República e em capitais com baixo número de óbitos por covid-19 serão bem-sucedidos nas eleições municipais de 2020 se reelegendo ou fazendo o sucessor.

O presente artigo está estruturado em quatro seções e considerações finais, além desta introdução. A primeira seção abordará a forma como se deu a articulação federativa para se combater a pandemia da covid-19. A seção destaca a descoordenação federativa e a inação do Executivo federal, que fez com que estados e municípios assumissem as principais ações de combate à pandemia. A segunda aborda o tema das eleições municipais, ressaltando o aspecto contextual da covid-19. Na terceira seção é apresentado o desenho de pesquisa destacando a técnica de análise QCA. Ademais, expõe também as condições causais e o resultado de interesse, assim como a operacionalização e a justificativa teórica que fundamenta o desenho escolhido. A análise QCA será realizada na quarta e última seção em conformidade com o protocolo preconizado para utilização da técnica (PÉREZ-LIÑAN, 2010). Nas considerações finais, ressaltam-se os principais achados do artigo.

\section{Ausência de coordenação federal e implicações sobre o arranjo federativo}

A pandemia de covid-19 chega ao Brasil oficialmente em 26 de fevereiro de 2020, quando o primeiro caso de infecção por coronavírus é confirmado em um cidadão brasileiro. Além dos inúmeros desafios sanitários e socioeconômicos que a pandemia trouxe para o país, o momento histórico vivido foi também marco de tensões relativas à coordenação da crise e, principalmente, quanto à descoordenação entre os entes federados.

Considerando-se o federalismo moderno, originado nos Estados Unidos em 1787, observa-se que este se contrapõe ao Estado unitário e ao Estado confederado, podendo ser definido como um modo de organizar o poder político em uma via de dupla autonomia territorial, uma central, por meio de um governo nacional, e outra descentralizada, por governos subnacionais (SOARES; MACHADO, 2018).

No caso do modelo federativo brasileiro, consolidado na Constituição de 1988, descentralizaram-se recursos e poder político (SOUZA, 1997; SOUZA, 
1994; SOUZA, 1992), mantendo-se, porém, amplas atribuições ao executivo federal. Desse modo, construiu-se no país um arranjo que integrou, ao mesmo tempo, coordenação e cooperação, tanto vertical quanto horizontal, em todo o ciclo de vida das políticas públicas. Sendo o governo federal aquele que concentra os maiores poderes para a feitura de políticas sociais e que, segundo Arretche (2004), apesar das tendências centrífugas da descentralização fiscal e da fragmentação partidária, é o ente dotado de maior capacidade de coordenação de políticas públicas elaboradas no âmbito federal.

No caso das políticas de saúde, a Constituição de 1988, em seu artigo 198, normatizou que "as ações e serviços públicos de saúde integram uma rede regionalizada e hierarquizada e constituem um sistema único", contendo, além disso, parágrafo único que dispõe que "o sistema único de saúde será financiado, [...], com recursos do orçamento da seguridade social, da União dos Estados, do Distrito Federal e dos Municípios, além de outras fontes", o que indica a forte expectativa de ação de um "federalismo cooperativo" (RIBEIRO et al., 2018, p. 1780). Chama atenção também a complexidade dos mecanismos de governança tripartite para que o sistema funcione bem, sendo, dessa forma, atribuições da União, o planejamento, a indução e a coordenação nacional. Cabe aos Estados "a coordenação no plano regional e aos municípios, [...] o planejamento local, [...] a prestação direta de ações, serviços de cuidados primários e de média complexidade" (RIBEIRO et al., 2018, p. 1780).

Compreende-se que a coordenação federativa de políticas públicas no Brasil está relacionada às formas de integração, compartilhamento e decisão conjunta presentes nas federações (ABRUCIO, 2005). Nesse sentido, há quatro modelos de coordenação vertical possíveis no país: a) implementação local e recursos partilhados; b) gestão compartilhada com poucos recursos partilhados; c) pequena responsabilidade local e total financiamento e implementação federal; d) gestão e financiamento totalmente federal (PESSOA JR.; RUBIATTI, 2020; SOUZA, 2018). Especificamente em relação à área da saúde brasileira, o modelo de coordenação aplicado se enquadra no primeiro tipo. Por isso, no enfrentamento da pandemia, esperava-se que a União, dada sua centralidade jurisdicional, fizesse a coordenação, a formulação e a distribuição de recursos para a construção da política pública, mas não foi isso que aconteceu no Brasil (PESSOA JR.; RUBIATTI, 2020). 
A ausência de uma coordenação política no âmbito federal, as orientações controversas no próprio governo, as atitudes negacionistas e anticientificistas do presidente da República, Jair Bolsonaro, impuseram limites às ações de prefeitos e governadores (SANTANA, 2020b). Em determinadas situações, impuseram até um aumento das dificuldades de ação, como apontaram Ajzenman, Cavalcanti e da Mata (2020) em estudo sobre os efeitos da liderança em uma crise da pandemia de covid-19, no qual atestaram o forte efeito de persuasão por parte do chefe de estado, Bolsonaro, sobre o comportamento em localidades onde ele tinha a maioria dos apoiadores. Verificou-se, inclusive, uma "diminuição significativa no distanciamento social em municípios pró-governo após os eventos mais visíveis do presidente contra o comportamento e as políticas de autoisolamento" (AJZENMAN; CAVALCANTI; DA MATA, 2020, p. 16, tradução nossa). Cabral, Ito e Pongeluppe (2021) também concluíram que a liderança negacionista do presidente Jair Bolsonaro gerou graves consequências, tanto que os municípios em que obteve maior apoio político são aqueles com maior número de casos de covid-19 e mortes relacionadas à doença. Essa situação indica, segundo os autores supracitados, que as populações que apoiam um líder negacionista são as principais vítimas de seu estilo de liderança (CABRAL; ITO; PONGELUPPE, 2021, p. 2).

Nesse cenário, a inépcia federal, além disso, também inviabilizou que a estrutura e os recursos disponíveis no Sistema Único de Saúde (SUS) fossem utilizados de forma adequada nos municípios (NUNES et al., 2020). De acordo com Fernandez e Fernandes (2020), uma das fragilidades da estratégia nacional foi exatamente a pouca participação dispensada à Atenção Primária da Saúde (APS) na condução da crise sanitária.

De forma global, as respostas dos governos à pandemia variaram, o que tem relação tanto com o formato institucional dos países (SCHAEFER et al., 2020), mas também com o comportamento dos seus chefes de estados. No Brasil, devido às significativas discrepâncias socioeconômicas entre os entes federados, a capacidade de proposição e a execução de políticas públicas encontram-se vinculadas a uma ação efetiva do Executivo federal, sobretudo a dimensão de formulação e disponibilização de recursos para políticas públicas de saúde, educação e assistência social. Com a ausência de orientações nacionais acerca das restrições à circulação de pessoas em território nacional, especialmente nos locais com maior 
incidência de casos suspeitos e/ou mortes por covid-19, de restrição de atividades não essenciais e de adoção de medidas sanitárias não farmacológicas, as tomadas de decisões ficaram a cargo dos chefes dos Executivos subnacionais. E, nessa situação, governadores e diversos prefeitos tornaram-se protagonistas na adoção de medidas importantes (ROCHA, 2020a; ROCHA; ALMEIDA; CORRÊA, 2020; SANTANA; PEREZ, 2020).

Desse modo, dado que o governo federal não chegou a um consenso em relação às medidas de distanciamento social, coube ao Judiciário, inclusive, definir como legítima a atuação dos governos subnacionais na adoção de ações e estratégias para o enfrentamento à pandemia. Em 15 de abril de 2020, o Supremo Tribunal Federal (STF) decidiu, por unanimidade, que medidas adotadas pelo governo federal na Medida Provisória 926/2020, para o enfrentamento da pandemia dentro do território nacional, não afastariam a competência concorrente, nem a tomada de providências normativas e administrativas pelos estados, pelo Distrito Federal e pelos municípios. A decisão foi no sentido de resguardar a autonomia dos entes e o princípio da separação dos poderes.

Nesse contexto, o que se viu foram governos subnacionais atuantes, sendo que as primeiras ações locais se iniciaram antes mesmo da decretação da situação de pandemia. Vários estados e municípios se mobilizaram para a adoção de planos de contingências e/ou para a execução de ações preparatórias como a criação de comitês gestores e científicos para a definição de estratégias de enfrentamento da doença (ROCHA, 2020a). A partir de 11 de março, quando a Organização Mundial da Saúde (OMS) reconheceu a crise sanitária com o status de pandemia, viu-se que os primeiros decretos dos Executivos subnacionais começaram a ser promulgados.

As medidas variaram bastante na comparação entre os estados e, também, os municípios. A maioria dos decretos estaduais versava sobre o fechamento do comércio e serviços não essenciais, suspensão de atividades educacionais presenciais, proibição de eventos públicos, aglomerações, proibição da circulação de transporte intermunicipal, distanciamento social, além de novas rotinas administrativas no âmbito dos governos (SANTANA; PEREZ, 2020). No âmbito municipal, medidas diversas foram adotadas nas áreas administrativas, voltadas a contenção, mitigação e supressão, bem como ações de compensação econômica, de assistência social, saúde, sanitização da cidade e conscientização/comunicação (ROCHA, 2020a; ROCHA; ALMEIDA; CORRÊA, 2020; NUNES et. al., 2020). 
Segundo Nunes e colaboradores (2020), dois momentos caracterizam a forma como gestores municipais lidaram com a pandemia, os quais foram definidos pelo modo como se deu a evolução epidemiológica no Brasil. Conforme os autores, desde o início da pandemia, o Brasil experimentou uma consolidação de números altos de casos e óbitos, ou seja, um "platô", em vez de se verificar um padrão como o observado na Europa, em que se atingiu rapidamente um pico, também seguido de um decréscimo da curva. A consequência foi que o país transitou de uma política de combate à pandemia ( $1^{\circ}$ momento) para uma política de convivência ( $2^{\circ}$ momento). O primeiro momento foi de março até agosto de 2020, caracterizando-se pela adoção de medidas rígidas de isolamento social e com ações hesitantes em termos de saúde pública, como fechamentos de Unidades Básicas de Saúde (UBS), o que dificultou as políticas de implementação de barreiras sanitárias, testagem e rastreamento de contatos. O segundo, iniciado em setembro de 2020, foi marcado pela reabertura gradual ou total das atividades consideradas não essenciais, minimização dos conflitos entre prefeituras e outros atores sociais, sobretudo comerciantes e adoção de gestão da crise baseada em aprendizado. Foi nesse segundo momento que ocorreram as eleições municipais de 2020.

\section{Pandemia e sucesso eleitoral}

Diante de um cenário de descoordenação federal e de desorganização em relação ao comando das políticas de saúde para o enfrentamento da pandemia, observou-se no Brasil uma "tomada de frente" dos demais entes federados, prefeituras e governos nos estados, o que gerou uma heterogeneidade de iniciativas e medidas, mais ou menos pautadas nas indicações das organizações de saúde internacionais, como a OMS. Em meio a esse amplo espectro, foi possível verificar prefeitos e governadores que optaram mais fortemente pela proteção da saúde dos indivíduos, empregando isolamento à população. Já outros governantes entenderam que a principal preocupação era econômica, mantendo-se, assim, desalinhados ao que se recomendava pelos especialistas em saúde pública.

Desse contexto, alguns estudos seminais sobre as relações entre a atuação na pandemia e eleições e a confiança nos atores políticos têm sido publicizados e apontam para perspectivas interessantes. Primeiro, tem de se ter em 
mente que, em crises agudas, desloca-se a percepção dos cidadãos em relação ao governo, como apontam Pereira, Medeiros e Bertholini (2020). Ao analisarem as opiniões dos eleitores em relação ao governo executivo federal, esses autores afirmam que "a covid-19 fez com que segmentos expressivos de eleitores alterassem sua percepção política diante do 'medo da morte"' (PEREIRA; MEDEIROS; BERTHOLINI, 2020, p. 954). Dessa forma, ao tomarem conhecimento de vítimas fatais próximas ao seu convívio, os indivíduos se tornam mais favoráveis e predispostos ao isolamento e passam, então, a avaliar negativamente o presidente e em melhor nível (positivamente) os governadores (PEREIRA; MEDEIROS; BERTHOLINI, 2020).

Pesquisadores que analisaram casos em outros países mostram que a percepção acerca das medidas de enfrentamento mais rígidas e as eleições vão para o mesmo caminho. Giommoni e Loumeau (2020), ao analisarem as eleições locais na França, perceberam que as cidades que tiveram rigidez mais longa de medidas exibiram maior apoio ao incumbente. De acordo com os pesquisadores, isso pode ter a ver com o fato de que esses eleitores se sentiram mais seguros ou até se tornaram mais conscientes em relação à seriedade da crise sanitária vivida (GIOMMONI; LOUMEAU, 2020). Ademais, em estudo sobre países da Europa Ocidental, Bol e colaboradores (2021) afirmam que, apesar das consequências negativas humanas e econômicas da imposição de uma contenção mais restrita para o combate do coronavírus, o apoio político ao incumbente logo após as decisões demonstram níveis mais elevados, ou seja, os cidadãos compreendem ser necessária uma maior restrição, o que aumentou, inclusive, as intenções de votos nesses políticos (BOL et al., 2021).

No entanto, é importante que se entenda que, no caso brasileiro, há especificidades em jogo, o que impede que sejam esperados os mesmos diagnósticos dos casos europeus, principalmente pelo contexto socioeconômico da população, que, antes mesmo da pandemia, já vivia em um cenário no qual ampla parcela dos cidadãos se encontrava em situação de pobreza e extrema pobreza ${ }^{9}$. Mesmo diante desse panorama, o governo federal brasileiro não construiu um programa de auxílio emergencial robusto, possibilitando

9 Antes da pandemia estavam em situação de pobreza "33\% das mulheres negras, 32\% dos homens negros e $15 \%$ das mulheres brancas e dos homens brancos" (NASSIF-PIRES; CARDOSO; OLIVEIRA, 2021, p. 2), já em situação de extrema pobreza eram " $9,2 \%$ entre mulheres negras, $8,9 \%$ entre homens negros, $3,5 \%$ entre mulheres brancas e 3,4\% entre homens brancos" (NASSIF-PIRES; CARDOSO; OLIVEIRA, 2021, p. 2). 
que a população se sustentasse durante a pandemia, o que pode ter prejudicado os índices de isolamento do país ${ }^{10} \mathrm{e}$ até a confiança nos atores políticos que decretaram isolamento. Especificamente, sobre o auxílio emergencial, inicialmente foram feitos pagamentos de cinco parcelas de $\mathrm{R} \$ 600,00$ nos meses de abril, maio, junho, julho e agosto. Depois, os valores foram reduzidos e passaram para $\mathrm{R} \$ 300,00$ a serem pagos por mais quatro meses (setembro, outubro, novembro e dezembro de 2020). O auxílio foi completamente cortado entre janeiro e março de 2021 e só retomado em abril de 2021 com um valor de $\mathrm{R} \$ 150,00$ por quatro meses ${ }^{11}$. Todo esse contexto fez com que prefeitos se encontrassem em uma situação de trade-off entre optar por seguir o isolamento social recomendado pela comunidade científica ou abrir o comércio e as atividades econômicas defendidas por atores locais (MARENCO; TEN CATE, 2021; BATISTA, 2020; GRIN, 2020).

Assim, a política se tornou pano de fundo dos posicionamentos dos prefeitos perante à questão. Ou seja, não somente questões técnicas, como saúde pública e a economia, pautaram as decisões, o alinhamento ou discordância ao governo federal também influenciou as ações adotadas no Brasil. Especificamente nos casos dos prefeitos, que são as unidades de análise deste trabalho, um mix de variáveis técnicas e políticas estava nas justificativas usadas para a tomada das decisões.

É fato que os governos locais são responsáveis e têm um amplo espectro de prerrogativas no federalismo brasileiro, desde

[...] proteção do patrimônio histórico e cultural, regulamentação do uso e da ocupação do solo, pela organização e prestação de serviços públicos de interesse local (como saúde, educação, transporte público e assistência social), bem como alguns programas focalizados de transferência condicionada de renda (BRAMBOR; CENEVIVA, 2012, p. 10).

10 O índice de isolamento social do Brasil nunca chegou a 70\%. A maior taxa alcançada foi de 62,2\% em 23 março de 2020. Disponível em: https://veja.abril.com.br/blog/maquiavel/covid-brasil-nunca-fez-o-minimo-de-isolamentosocial-para-deter-o-virus/. Acesso em: 8 maio 2021.

11 De acordo com Nassif-Pires, Cardoso e Oliveira (2021), com a queda do auxílio emergencial em 2021, no Brasil, $38 \%$ das mulheres negras, $36 \%$ dos homens negros, $19 \%$ das mulheres brancas e dos homens brancos estão em situação de pobreza; e em extrema pobreza estão " $9,2 \%$ entre mulheres negras, 8,9\% entre homens negros, 3,5\% entre mulheres brancas e 3,4\% entre homens brancos" (NASSIF-PIRES; CARDOSO; OLIVEIRA, 2021, p. 2). 
Além disso, a autonomia dos municípios enquanto entes federados autônomos, os quais não estão subordinados a estados e à União (BRAMBOR; CENEVIVA, 2012), faz com que sejam centrais no panorama da organização política brasileira, o que, por consequência, coloca prefeitos como atores políticos relevantes no cenário político-eleitoral.

Muitas vezes a performance de prefeitos é observada mais facilmente por eleitores do que o desempenho do presidente da República, isso porque "o prefeito é o principal gerente dos serviços públicos diretamente fornecidos à população" (MENDES, ROCHA, 2004, p. 6), tornando-se, portanto, a figura política mais facilmente identificada (MENDES; ROCHA, 2004). Desse modo, segundo constataram Mendes e Rocha (2004), a performance administrativa do prefeito reflete parte do resultado eleitoral, assim como variáveis que têm a ver com as resultantes de políticas públicas de saúde e educação.

No caso da pandemia de covid-19, há um plus na centralidade da atuação dos prefeitos, já que 2020, o primeiro ano em que o Brasil sofreu com a contaminação pela doença, também foi o ano de eleições municipais, o que fez com que perguntas e respostas sobre a atuação em relação à pandemia fossem colocadas e tivessem um peso inclusive no sucesso eleitoral dos prefeitos.

Entende-se, aqui, sucesso eleitoral como a reeleição do incumbente cabendo lembrar que, desde a Emenda Constitucional 16, de 4 de junho de 1997, todos que ocupam cargos majoritários dispõem desse direito. Ademais, também se considera sucesso eleitoral quando o indicado do prefeito em exercício vence o pleito.

Codato, Cervi e Perissinotto (2013), em estudo envolvendo $5.567 \mathrm{mu}-$ nicípios brasileiros, levantaram que as variáveis a explicarem o sucesso eleitoral de candidatos às prefeituras são de natureza política, afinal, "ser candidato à reeleição, fazer parte de uma coligação partidária e estar na disputa em um partido com alto desempenho são as principais explicações para a aquisição do mandato municipal". Já Marenco e Ten Cate (2021) salientam que a disputa pelas cadeiras de prefeito e de vereadores especificamente em 2020 foi moldada pela combinação de três fatores: " [I] efeitos da pandemia de covid-19 e as respostas de autoridades federais, estaduais e municipais a ela, [II] mudanças na legislação eleitoral e por [III] campanhas eleitorais com duração temporal mais curta" (MARENCO; TEN CATE, 2021, p. 26). 
Neste trabalho, foram analisadas variáveis políticas, bem como o seu impacto no sucesso eleitoral dos candidatos às prefeituras das capitais. Considerando-se o contexto histórico excepcional e o protagonismo de prefeitos, foram investigadas ainda se as variáveis relativas às medidas de saúde pública afetaram o sucesso eleitoral dos prefeitos.

\section{Metodologia e condições analisadas}

Este artigo busca responder se as condições políticas e de gestão de saúde pública, conjuntamente, impactam o sucesso eleitoral de prefeitos das capitais no pleito de 2020.

Para tanto, o modelo compreende quatro condições causais, sendo duas relativas à saúde pública e as outras duas políticas. São elas: (i) a aprovação do prefeito; (ii) o grau de rigidez das medidas de distanciamento social; (iii) a taxa de óbitos por 100 mil habitantes; e (iv) alinhamento do prefeito ao presidente da República ${ }^{\mathbf{1 2}}$.

A priori, esperava-se que alcançariam sucesso eleitoral os prefeitos com alta aprovação, os quais instituíram medidas rígidas de isolamento, estavam à frente de cidades com baixa taxa de óbitos (valores comparados) e ainda não se alinharam ao presidente da República.

Na próxima seção será apresentada a técnica de análise QCA, assim como a operacionalização das condições causais.

\section{Análise Comparativa Qualitativa (QCA)}

A Qualitative Comparative Analysis (QCA) é uma técnica desenvolvida por Ragin (1987) que parte do suposto que os fenômenos sociais dependem da ação conjunta de múltiplas causas, gerando diversas configurações causais, em virtude de fatores contextuais, caracterizando na ideia de causalidade conjuntural múltipla. Dito de outra forma, a interação entre duas ou mais variáveis explicativas (entendido na QCA como condições causais) podem resultar em inúmeras configurações que determinam a ocorrência de um fenômeno chamado de resultado de interesse (RAGIN, 1987; RIHOUX; RAGIN, 2009).

12 Outras variáveis poderiam ser inseridas no modelo, caso o método utilizado não fosse a QCA e se o número de casos fosse maior, como as variáveis: ideologia política do prefeito; e base bolsonarista. No entanto, com o propósito de garantir tanto parcimônia ao modelo quanto atenção às condições específicas que envolvem a pandemia de covid-19, optamos por trabalhar com quatro condições, ao mesmo tempo que asseguramos comparabilidade entre casos com igual peso político em seus estados: as capitais. 
Desse modo, a técnica permite tratar de fenômenos que podem tanto ser resultado da combinação de diferentes condições causais (multicausalidade) quanto gerar um mesmo resultado (equifinalidade). Nesse sentido, é possível perceber o nexo de causalidade conjuntural, ou seja, como as condições interagem entre si para produzir um dado fenômeno. São observadas também combinações que não levam ao resultado de interesse.

Admite-se, portanto, que as condições causais têm grau variável de participação para a ocorrência de um dado resultado considerando a interação entre as demais condições causais, o que sugere rotas alternativas (várias configurações) para a ocorrência do resultado de interesse. Depreende-se, assim, que uma condição de causalidade esteja contida em subconjunto de condições que produzem o resultado, verificando que a condição causal é suficiente, mas não necessária no sentido de ocasionar um determinado fenômeno.

Por fim, devemo-nos ater ao pressuposto da assimetria, a qual prevê que se uma condição $\mathrm{X}$ resulta em $\mathrm{Y}$, não necessariamente $\mathrm{Y}$ não ocorrerá na ausência de $\mathrm{X}$. O resultado de interesse é passível de ser observado por outro conjunto de configurações causais que não apresentam X (SCHNEIDER; WAGEMANN, 2012).

Por conseguinte, o método pode ser utilizado como técnica de análise multicausal para lidar com estudos que apresentem poucos casos (small-N/Medium-N) (PÉREZ-LIÑÁN, 2010; SANTOS; PÉREZ-LIÑÁN; GARCÍA MONTERO, 2014; SANDES-FREITAS; BIZARRO-NETO, 2015). Wagemann (2012) destaca que a técnica constitui um poderoso instrumento de inferência causal cruzada de dados ao vincular um resultado de interesse a condições causais, pois permite analisar todas as combinações possíveis das condições causais com o objetivo de observar quais condições são necessárias ou suficientes para a ocorrência do resultado de interesse (SANTOS; PÉREZ-LIÑÁN; GARCÍA MONTERO, 2014).

Essa técnica permite determinar um resultado específico de interesse e as condições sugeridas para impactar este resultado. Assim sendo, a análise QCA pode ser expressa matematicamente da seguinte forma:

$$
y=f\left(x_{1+} x_{2+} x_{3+} x_{4+\ldots} x_{n}\right)
$$


Y representa o fenômeno de interesse, que, conforme a equação, está em função da combinação de múltiplas condições causais (X1, X2, X3 ... Xn). Para o caso em análise, representa o sucesso eleitoral nas eleições para prefeito das capitais brasileiras no ano de 2020. Trata-se de um outcome dicotômico, no qual 0 representa insucesso, e 1, sucesso.

Quanto às condições causais, foram consideradas quatro condições favoráveis ou desfavoráveis aos prefeitos nas eleições em um contexto de pandemia de covid-19. X1 refere-se à aprovação do prefeito em exercício pela população, sendo operacionalizada de forma binária, em que 0 é desaprovado e 1 aprovado. Já X2 diz respeito às medidas de isolamento social adotadas pelos prefeitos das capitais. Essa medida admite três valores: 0 significa baixa rigidez; 1 rigidez intermediária; e 2 medidas rigorosas de isolamento social. X3 é a taxa de óbitos por covid-19 por 100 mil habitantes. Novamente, tem-se uma condição que admite três valores, sendo 0 correspondente a baixo número de mortes; 1 relativo a valores intermediários; e 2 associado às capitais com um número elevado de mortes. A última condição X4 refere-se à aproximação entre prefeitos e governo federal e admite os valores 0 e 1 respectivamente para alinhamento e não alinhamento. Desse modo, o modelo de análise é expresso da seguinte maneira:

$$
\mathrm{Y}_{\text {Sucesso eleitoral }}=f\left(\mathrm{x}_{\text {aprovação }+} \mathrm{x}_{\text {índice Ipea }+} \mathrm{x}_{\text {taxa de óbitos }+} \mathrm{x}_{\text {alinhamento presidente }}\right)
$$

Descrito de forma extensiva, o modelo aqui formulado e testado sugere que o sucesso eleitoral nas eleições municipais (Y) ocorre em função da combinação entre aprovação do prefeito (X1), a rigidez das medidas de distanciamento social (X2), taxa de óbitos no município (X3) e o alinhamento com o presidente (X4). Assim, o modelo e o teste utilizando QCA nos orientarão a explicar os casos de resultados 1, ou seja, situações em que o prefeito foi reeleito ou fez o sucessor.

Entre os três tipos de QCA, explicitados por Ragin (2000), crisp-set, multi-value e fuzzy-set, optou-se, para testar o modelo, o tipo de análise multi-value (mvQCA), em que as condições podem assumir mais de duas categorias $(0,1,2$ e 3 , por exemplo). Justifica-se a escolha pelo fato de duas condições causais mobilizadas assumirem mais de dois valores, conforme ficará 
claro na exposição da operacionalização das condições causais e das justificativas teóricas que se seguem.

\section{Condições causais}

\section{a) Aprovação do prefeito}

A primeira condição a ser operacionalizada é a aprovação dos prefeitos, pois, em uma perspectiva do voto racional, as razões do voto do eleitor têm indicado a sua escolha eleitoral em função de fatores retrospectivos e prospectivos relacionados ao desempenho dos governos, procedendo, dessa maneira, a uma avaliação de desempenho dos governantes (DOWNS, 2013; FIGUEIREDO, 1991).

Estudos específicos sobre eleições municipais para o executivo no Brasil apontam que a avaliação positiva da administração municipal aumenta as chances de se votar no candidato à reeleição (BORBA; CERVI, 2017; VEIGA; SANTOS; NEVES, 2011). Assim sendo, prefeitos bem avaliados e, consequentemente, aprovados pela população tendem a ser reeleitos. Partimos da suposição de que prefeitos bem avaliados, não candidatos à reeleição, podem utilizar seu capital político para viabilizar a eleição de sucessores, aumentando as possibilidades desses candidatos de serem eleitos.

Em geral, os pesquisadores têm recorrido à avaliação dos prefeitos a partir das categorias utilizadas pelas pesquisas de opinião: ótimo, bom, regular, ruim e péssimo. Um prefeito bem avaliado seria, então, aquele avaliado como "bom" ou "ótimo". No entanto, não se sabe, ao certo, como categorizar um prefeito como "bem avaliado" ou "mal avaliado". Além disso, não se sabe se aqueles que respondem como "regular" aprovam ou não o prefeito. Por isso, optou-se por utilizar a aprovação como um indicador objetivo de se a população aprova ou não um dado prefeito.

A aprovação é reportada nas pesquisas de opinião variando de $0 \%$ a $100 \%$. Assim, a condição "aprovação" foi operacionalizada da seguinte forma: (i) "aprovados", prefeitos que obtiveram aprovação acima de 50\%; (ii) "não aprovados", prefeitos com aprovação abaixo de 50\%. Esse critério se baseou no fato de que um candidato necessita de mais de $50 \%$ dos votos válidos para serem eleitos. 
Tabela 1 - Aprovação dos prefeitos em exercício das capitais brasileiras, conforme dados do Ibope, de outubro a novembro, Brasil, 2020.

\begin{tabular}{|c|c|c|c|}
\hline Capital & Aprovação & Aprova & Desaprova \\
\hline Aracaju & 1 & $58 \%$ & $37 \%$ \\
\hline Belém & 0 & $13 \%$ & $83 \%$ \\
\hline Belo Horizonte & 1 & $76 \%$ & $22 \%$ \\
\hline Boa Vista & 1 & $87 \%$ & $10 \%$ \\
\hline Campo Grande & 1 & $53 \%$ * & - \\
\hline Cuiabá & 1 & $53 \%$ & $39 \%$ \\
\hline Curitiba & 1 & $68 \%$ & $29 \%$ \\
\hline Florianópolis & 1 & $72 \%$ & $22 \%$ \\
\hline Fortaleza & 1 & $66 \%$ & $29 \%$ \\
\hline Goiânia & 1 & $70 \%$ & $25 \%$ \\
\hline João Pessoa & 0 & $50 \%$ & $45 \%$ \\
\hline Maceió & 0 & $37 \%$ & $56 \%$ \\
\hline Manaus & 0 & $42 \%$ & $50 \%$ \\
\hline Natal & 1 & $63 \%$ & $31 \%$ \\
\hline Palmas & 1 & $57 \%$ & $36 \%$ \\
\hline Porto Alegre & 0 & $26 \%$ & $67 \%$ \\
\hline Porto Velho & 1 & $51 \%$ & $41 \%$ \\
\hline Recife & 0 & $37 \%$ & $57 \%$ \\
\hline Rio Branco & 0 & $44 \%$ & $47 \%$ \\
\hline Rio de Janeiro & 0 & $19 \%$ & $76 \%$ \\
\hline Salvador & 1 & $85 \%$ & $12 \%$ \\
\hline São Luís & 0 & $49 \%$ & $44 \%$ \\
\hline São Paulo & 1 & $52 \%$ & $39 \%$ \\
\hline Teresina & 0 & $41 \%$ & $53 \%$ \\
\hline Vitória & 0 & $48 \%$ & $47 \%$ \\
\hline
\end{tabular}

Fonte: elaboração própria a partir dos dados do Ibope, em pesquisas realizadas no período de outubro a novembro de 2020 e publicadas em jornais de grande circulação do país (Folha de S. Paulo, G1 e Gazeta).

Nota: $\left(^{*}\right)$ em Campo Grande, não foi possível obter a informação sobre aprovação, por isso, utilizou-se a somatória das avaliações positivas ("ótima" e "boa") como proxy para aprovação do prefeito.

Espera-se que os candidatos de situação, vinculados a prefeitos bem avaliados, sejam eleitos, sobretudo, em um contexto em que o combate à pandemia de covid-19 impõe um papel fundamental aos prefeitos. 
b) Rigidez das medidas de distanciamento social

A condição no modelo construído neste artigo é a de "rigidez das medidas", que também se classifica como aquela relativa às ações no campo da saúde pública e tem a ver com as medidas tomadas pelos prefeitos para garantir o distanciamento social entre as pessoas ao longo da pandemia de covid-19. Essa condição de fato assume importância no modelo aqui construído, já que, ao longo do ano de 2020, consolidou-se o entendimento de que a alta transmissibilidade do novo coronavírus estava ligada à sua contaminação a partir de "gotículas contaminadas de secreções orofaringe de uma pessoa infectada para uma pessoa livre de infecção, pelo contato com superfícies e objetos contaminados, onde o vírus pode permanecer viável por até 72 horas, ou via fecal-oral" (AQUINO et al., 2020, p. 2425) - situação que indica a importância de medidas de distanciamento social com o intuito de reduzir as interações entre pessoas infectadas ainda não identificadas ${ }^{13}$ e pessoas não infectadas (AQUINO et al., 2020).

A partir desse diagnóstico, os executivos municipais tomaram uma série de medidas para normatizar o distanciamento social. A partir dessas iniciativas, o Ipea, na pesquisa Physical distancing measures in Brazil, gerou um índice de distanciamento social a partir do qual se pontuam diariamente as cidades (MORAES, 2020).

$\mathrm{O}$ índice mede o grau de rigidez das medidas de distanciamento social e é composto pela soma dos valores de seis variáveis: (i) se a realização de eventos, assim como o funcionamento de estabelecimentos culturais, esportivos ou religiosos foi suspensa; (ii) se as atividades de bares, restaurantes e similares foram suspensas; (iii) se as atividades de estabelecimentos comerciais e de serviços em geral (exceto os essenciais) foram suspensas; (iv) se as atividades de estabelecimentos industriais (exceto os essenciais) foram suspensas; ( $v$ ) se as aulas foram suspensas; e ( $v i$ ) se foram introduzidas restrições ao transporte de passageiros. Foram atribuídos os valores de 2, 1 ou 0 conforme a suspensão ou restrição fosse total, parcial ou inexistente, para todas as variáveis. Como a soma dos valores variava entre 0 e 12 (por serem seis variáveis), os valores do índice foram ajustados para que estivessem entre 0 e 10 (uma escala mais intuitiva), sendo que 10 são os casos de maiores restrições (MORAES, 2020).

13 Pessoas infectadas devem permanecer em quarentena. 
Considerados os impactos socioeconômicos das medidas de distanciamento social na vida dos cidadãos, estas foram trazidas ao modelo no sentido de hipotetizar que o nível de restrição a que as pessoas foram expostas pode ter afetado seu julgamento em relação ao líder do executivo municipal (PEREIRA; MEDEIROS; BERTHOLINI, 2020; GIOMMONI, LOUMEAU, 2020; BOL et al., 2021).

A análise aqui empreendida utilizou a mediana do Índice do Ipea, calculado para o período de 11 de março de 2020, quando a OMS declara a condição de pandemia de covid-19, até o dia 07 de junho de 2020, último registro da base de dados do Ipea. Cabe ressaltar que em junho o Brasil estava no pico de óbitos da primeira onda'14 (FIOCRUZ, 2021). Apesar de terem sido investigados resultados eleitorais, avaliou-se que seria interessante utilizar os dados do Ipea para a primeira onda, por apresentarem uma heterogeneidade de cenários, desde o início da pandemia até o pico de casos. Além disso, os dados têm o afastamento necessário do período de campanha eleitoral e das eleições, o que permite que haja menos chances de vieses em relação ao comportamento de incumbentes em período pré-eleitoral e eleitoral.

Em resumo, o interesse nesse ponto da investigação tem a ver com as razões para se acreditar nas possíveis consequências econômicas ou na difusão e aumento do número de óbitos em virtude da covid-19 sobre o resultado eleitoral.

Portanto, esperava-se dos prefeitos medidas mais restritivas, ao longo do período destacado. Por isso, utilizou-se a mediana em vez da média ou de outras formas de operacionalizar a condição, por se tratar de uma medida de tendência central que separa as capitais em grupos distintos, conforme o tempo em que estiveram sob medidas de restrição e distanciamento social.

Observa-se a existência de três grupos de casos: aqueles com menor rigidez; outros de maior rigidez; e contingente de rigidez intermediária. Isso serviu para operacionalizarmos uma das condições do modelo de análise proposto. Por falta de um debate mais consolidado teoricamente sobre os limiares (thresholds) para essa condição, optou-se, assim, por uma condição tricotômica, dado que a dicotômica poderia agregar casos com diferentes situações

14 Ressaltamos que os dados do Ipea têm como recorte o cenário caracterizado como a primeira onda da covid-19 no Brasil. Os números de casos e mortes começam a decrescer no final de agosto e início de setembro de 2020. 
em um mesmo grupo. Desse modo, dividiu-se em três grupos: 0 para indicadores até 4,9; 1, acima de 4,9 até 6,9; e 2, acima de 7,0 até 10 (ver Tabela 2).

Tabela 2 - Mediana do índice de regras de distanciamento social nas capitais do Brasil, conforme dados do Ipea, 11 de março a 7 de junho, Brasil, 2020.

\begin{tabular}{|c|c|c|}
\hline Capital & $\begin{array}{c}\text { Mediana } \\
\text { Índice do Ipea }\end{array}$ & $\begin{array}{l}\text { Rigidez das } \\
\text { medidas }\end{array}$ \\
\hline Cuiabá & 2,5 & 0 \\
\hline Curitiba & 2,5 & 0 \\
\hline Fortaleza & 2,5 & 0 \\
\hline Natal & 2,5 & 0 \\
\hline Rio Branco & 2,5 & 0 \\
\hline São Luís & 2,5 & 0 \\
\hline Florianópolis & 3,3 & 0 \\
\hline Goiânia & 3,3 & 0 \\
\hline Belém & 5 & 1 \\
\hline Campo Grande & 5 & 1 \\
\hline Salvador & 5 & 1 \\
\hline Maceió & 5,8 & 1 \\
\hline Palmas & 5,8 & 1 \\
\hline Aracaju & 6,7 & 1 \\
\hline Boa Vista & 6,7 & 1 \\
\hline Manaus & 6,7 & 1 \\
\hline Recife & 6,7 & 1 \\
\hline São Paulo & 6,7 & 1 \\
\hline Vitória & 6,7 & 1 \\
\hline Belo Horizonte & 7,5 & 2 \\
\hline Porto Velho & 7,5 & 2 \\
\hline Rio de Janeiro & 7,5 & 2 \\
\hline João Pessoa & 8,3 & 2 \\
\hline Porto Alegre & 8,3 & 2 \\
\hline Teresina & 9,2 & 2 \\
\hline
\end{tabular}

Fonte: elaboração própria a partir dos dados do Ipea (Physical distancing measures in Brazil). Disponível em: https:// docs.google.com/spreadsheets/d/1a5_eloeGJkTWC6V4J39Qbbbm2wMPQlzcTeBxPy-hu80/edit?ts=5fb6a9ad\#gid=0.

\section{c) Taxa de óbitos}

Entre as condições que compõem o modelo aqui apresentado está a taxa de óbitos por cem mil habitantes por capital. Ao longo da pandemia, os governos no mundo miraram ações que pudessem diminuir o número de óbitos. Diante desse 
fato, a hipótese é que o número de mortos poderia impactar a avaliação dos prefeitos das cidades analisadas e, consequentemente, afetar o sucesso eleitoral dos incumbentes na tentativa de se reeleger ou de eleger seus indicados ao cargo (PEREIRA; MEDEIROS; BERTHOLINI, 2020). Na ausência de uma discussão consolidada na literatura que classifique a condição "taxa de morte" nas capitais brasileiras, considerou-se a distribuição dos dados mais atualizados de mortes antes da realização das eleições no primeiro turno como condição, em 13 de novembro de 2020.

Tabela 3 - Óbitos por 100 mil habitantes por capital brasileira, 13 de novembro, Brasil, 2020

\begin{tabular}{|c|c|c|c|c|c|}
\hline Capital & População* & Mortes & Taxa de mortes & $\begin{array}{l}\text { Taxa de mortes } \\
\text { (dicotômica) }\end{array}$ & $\begin{array}{l}\text { Taxa de mortes } \\
\text { (tricotômica) }\end{array}$ \\
\hline Florianópolis & 508.826 & 190 & 37,34 & 0 & 0 \\
\hline Belo Horizonte & 2.521 .564 & 1558 & 61,79 & 0 & 0 \\
\hline Palmas & 306.296 & 194 & 63,34 & 0 & 0 \\
\hline Campo Grande & 906.092 & 724 & 79,90 & 0 & 0 \\
\hline Curitiba & 1.948 .626 & 1578 & 80,98 & 0 & 0 \\
\hline Salvador & 2.886 .698 & 2690 & 93,19 & 0 & 1 \\
\hline Porto Alegre & 1.488 .252 & 1391 & 93,47 & 0 & 1 \\
\hline Maceió & 1.025 .369 & 1024 & 99,87 & 0 & 1 \\
\hline Rio Branco & 413.418 & 440 & 106,43 & 0 & 1 \\
\hline Natal & 890.480 & 949 & 106,57 & 0 & 1 \\
\hline São Paulo & 12.325 .232 & 13.828 & 112,19 & 0 & 1 \\
\hline São Luís & 1.108 .975 & 1265 & 114,07 & 0 & 1 \\
\hline Goiânia & 1.536 .097 & 1776 & 115,62 & 0 & 1 \\
\hline Boa Vista & 419.652 & 514 & 122,48 & 1 & 1 \\
\hline Aracaju & 664.908 & 823 & 123,78 & 1 & 1 \\
\hline João Pessoa & 817.511 & 1043 & 127,58 & 1 & 1 \\
\hline Teresina & 868.075 & 1141 & 131,44 & 1 & 1 \\
\hline Manaus & 2.219 .580 & 2.974 & 133,99 & 1 & 1 \\
\hline Vitória & 365.855 & 506 & 138,31 & 1 & 1 \\
\hline Porto Velho & 539.354 & 789 & 146,29 & 1 & 2 \\
\hline Fortaleza & 2.686 .612 & 4014 & 149,41 & 1 & 2 \\
\hline Recife & 1.653 .461 & 2494 & 150,84 & 1 & 2 \\
\hline Belém & 1.499 .641 & 2282 & 152,17 & 1 & 2 \\
\hline Cuiabá & 618.124 & 1047 & 169,38 & 1 & 2 \\
\hline Rio de Janeiro & 6.747 .815 & 12419 & 184,04 & 1 & 2 \\
\hline
\end{tabular}

Fonte: elaboração própria a partir dos dados do Consórcio de Veículos de Imprensa e do Instituto Brasileiro de Geografia e Estatística (IBGE).

Legenda: $\left(^{*}\right)$ para população estimada para as cidades, ver: https://www.ibge.gov.br/cidades-e-estados. Acesso em: 7 dez. 2020.

Nota: Dados sobre óbitos nas capitais considerados até o dia 13/11/2020. Disponível em: https://especiais.g1.globo. com/bemestar/coronavirus/mapa-coronavirus/\#/. Acesso em 7 dez. 2020. 
Primeiramente, avaliou-se a possibilidade de se utilizar uma condição dicotômica (ver Tabela 3), separando-se as capitais em dois grupos iguais distinguidos pela mediana, mas se verificou que casos como Florianópolis e São Paulo, muito diferentes em termos de taxa de mortes, seriam encontrados no mesmo grupo. Logo, pensou-se em uma condição em mais categorias, baseada na distribuição dos valores. Foram empregados os seguintes thresholds para essa condição, levando-se em conta o grau de intensidade da taxa de óbitos por covid-19 nas capitais: 0 para valores até 90; 1, para valores acima de 90 até 140; e 2, para valores acima de $140^{15}$. Assim sendo, a distribuição dos valores dos três grupos foi organizada conforme a Tabela 3 e disposta como uma condição com três categorias, ou seja, propícia para a análise multi-value.

d) Alinhamento do prefeito com o presidente

Ao se analisar também o relacionamento do prefeito com o governo federal, notou-se que, em primeiro lugar, essa escolha transcorreu por se considerar que a política conduzida pelo chefe do executivo nacional é, de fato, aquela que afeta os atores políticos nos níveis federados. Além disso, em termos de gestão de saúde de um problema que impacta o país como um todo, é o presidente que constrói, dá continuidade ou pausa as políticas de Estado que repercutirão em toda a União. Especialmente no caso do enfrentamento da covid-19, o presidente da República afetou de forma importante o cenário visto nas realidades locais no Brasil (AJZENMAN; CAVALCANTI; DA MATA, 2020; CABRAL; ITO; PONGELUPPE, 2021).

Nesse sentido, o alinhamento com a presidência da República, dado o seu nítido negacionismo científico, pode ter causado impacto no sucesso eleitoral do prefeito.

Entende-se aqui que a retórica de "negacionismo científico", adotada por Jair Bolsonaro, mostrada antes mesmo da pandemia a partir, por exemplo, dos ataques às universidades e pesquisas científicas, teve continuidade no momento pandêmico (CAPONI, 2020), trazendo consigo as cinco características que marcam processos de negacionismo:

15 Por meio do gráfico de dispersão, observou-se a existência de três grupos de capitais agrupados, conforme a taxa de óbitos por covid-19. 
1) identificação de conspirações; 2) uso de falsos experts; 3) seletividade, focalizando em artigos isolados que contrariam o consenso científico ("cherry-picking”); 4) criação de expectativas impossíveis para a pesquisa; e 5) uso de deturpações ou falácias lógicas (CAMARGO JR., COELI, 2000, p. 2).

Nesse contexto, Jair Bolsonaro foi protagonista de uma série de falas polêmicas, de conteúdo anticientífico e contrário à vacinação. Empreendendo-se um levantamento de marcos retóricos do período de 2020 por parte do presidente, citam-se algumas a seguir. Em 9 de março de 2020, Bolsonaro afirmou que a questão do coronavírus estava sendo superdimensionada. Em 10 de março, disse que, no entender dele, a questão do coronavírus era muito mais uma fantasia. No dia 17 de março, apontou que a histeria em volta da questão estaria errada. Em 22 de março, sublinhou que haveria um alarmismo muito grande por parte da mídia em relação a essa questão. Em 23 de março, em pronunciamento nas redes de TV e rádio, o presidente falou que a covid-19 seria uma gripezinha. Já em 27 de março declarou que, infelizmente, algumas mortes iriam ocorrer, complementando: "paciência, acontece". Em 29 de março, expressou que as pessoas deveriam enfrentar o vírus "como homem". Em 3 de abril, ao comentar sobre 150 covas rasas abertas na cidade de São Paulo, comentou que a imprensa estaria fazendo "terrorismo" divulgando a imagem. Em 20 de abril, após ser indagado sobre 300 mortes naquele dia, respondeu: “Não sou coveiro, tá?”. Em 19 de maio, propagou: “Quem é de direita toma cloroquina, quem é de esquerda, Tubaína”. Em 2 de junho, minimizou as mortes pela doença, expondo o seu ponto de vista: "a gente lamenta todos os mortos, mas é o destino de todo mundo". Em 10 de novembro afirmou, "tudo agora é pandemia. [...] Tem que deixar de ser um País de maricas". Em 15 de dezembro, afirmou ainda: "Eu não vou tomar vacina e ponto final, problema meu" (O ESTADO DE S. PAULO, 2020; SANTANA; PEREZ; NASCIMENTO, 2021). Esse conjunto de afirmações indica que o prefeito alinhado a Bolsonaro também se manteve ao longo do tempo associado ao negacionismo científico encampado pelo governo.

Além disso, não foi só em discurso que Bolsonaro se manteve aquém da ciência, pois a sua inação na construção e coordenação de políticas públicas de 
enfrentamento à pandemia, principalmente no que tange à compra de equipamentos médicos, no planejamento do isolamento e de retomada da economia, resultaram na diminuição da eficácia e da eficiência das políticas de combate ao coronavírus (PESSOA JR.; RUBIATTI, 2020).

A partir desse contexto, apresenta-se a quarta condição chave deste trabalho, na qual se avalia o alinhamento de prefeitos de capitais em relação ao presidente Bolsonaro quanto ao enfrentamento da covid-19. A classificação abaixo foi feita com base no trabalho de Rômulo e colaboradores (2021) e Rocha e colaboradores (2020b). O trabalho de Rômulo e colaboradores (2021) fez uma compilação das análises descritas na série de artigos contidos em Santana e Perez (2020), Santana (2020a) e Santana (2020b), cujo projeto foi encampado por pesquisadores das 27 unidades federativas, que, entre outras coisas, observavam se havia alinhamento entre capitais, estados e União. Rocha e colaboradores (2020b) reúnem na série Os governos municipais frente o Coronavírus estudos realizados por diversos pesquisadores do país, analisando como as prefeituras enfrentam a pandemia.

A partir da leitura desses trabalhos, foi construída a classificação apresentada na Tabela 4, considerando-se o período de 11 de março de 2020 até o momento imediatamente anterior às campanhas eleitorais. Quando as ações e manifestações do prefeito eram contrárias à orientação do presidente, ele foi classificado como não alinhado. Levando-se em conta esse critério, constatamos que apenas o prefeito do Rio de Janeiro, Marcelo Crivella (Republicanos), assumiu uma postura alinhada ao presidente da República. Todos os outros prefeitos de capitais adotaram, em algum grau, ações e se posicionaram publicamente em favor do emprego de medidas baseadas no conhecimento científico. Tal posicionamento sugere que os prefeitos, por enfrentarem diretamente os problemas ocasionados pela crise sanitária, tenderam a adotar medidas responsáveis para conter o avanço da doença e evitar o colapso dos serviços de saúde. Dessa forma, chegou-se a uma distribuição dicotômica a partir da qual classificaram-se como "0" os prefeitos que não se alinharam a Bolsonaro e como " 1 " aqueles que se alinharam (Tabela 4). 
Tabela 4 - Alinhamento entre o prefeito da capital e o presidente da República em relação ao combate à covid-19, Brasil, 2020

\begin{tabular}{|c|c|c|}
\hline Capital & $\begin{array}{l}\text { Há alinhamento entre o prefeito } \\
\text { da capital e o presidente da } \\
\text { República? }\end{array}$ & Alinhamento ao presidente \\
\hline Aracaju & Não & 0 \\
\hline Belém & Não & 0 \\
\hline Belo Horizonte & Não & 0 \\
\hline Boa Vista & Não & 0 \\
\hline Campo Grande & Não & 0 \\
\hline Cuiabá & Não & 0 \\
\hline Curitiba & Não & 0 \\
\hline Florianópolis & Não & 0 \\
\hline Fortaleza & Não & 0 \\
\hline Goiânia & Não & 0 \\
\hline João Pessoa & Não & 0 \\
\hline Maceió & Não & 0 \\
\hline Manaus & Não & 0 \\
\hline Natal & Não & 0 \\
\hline Palmas & Não & 0 \\
\hline Porto Alegre & Não & 0 \\
\hline Porto Velho & Não & 0 \\
\hline Recife & Não & 0 \\
\hline Rio Branco & Não & 0 \\
\hline Rio de Janeiro & Sim & 1 \\
\hline Salvador & Não & 0 \\
\hline São Luís & Não & 0 \\
\hline São Paulo & Não & 0 \\
\hline Teresina & Não & 0 \\
\hline Vitória & Não & 0 \\
\hline
\end{tabular}

Fonte: elaboração própria a partir do trabalho de Rômulo e colaboradores (2021) e Rocha e colaboradores (2020b).

e) Resultado de interesse: sucesso eleitoral (reeleito ou sucessor eleito)

O resultado de interesse a ser analisado neste artigo é o sucesso eleitoral nas eleições municipais de 2020. São considerados casos de sucesso aqueles prefeitos que se candidatam à reeleição e lograram êxito, assim como prefeitos que conseguiram eleger sucessores, quando a reeleição não era uma opção. 
Em 13 das 25 capitais consideradas neste artigo o atual prefeito e/ou prefeita disputaram a reeleição. Destaca-se o caso de Iris Rezende do Movimento Democrático Brasileiro (MDB), que se retirou da vida pública e não disputou a prefeitura de Goiânia. Dos 13 que concorreram, 10 foram reeleitos: os prefeitos de Aracaju, Belo Horizonte, Campo Grande, Cuiabá, Curitiba, Florianópolis, Natal, Palmas, Porto Velho e São Paulo. Apenas Nelson Marchezan Júnior, do Partido da Social Democracia Brasileira (PSDB), Marcelo Crivella do Republicanos e Socorro Neri, do Partido Socialista Brasileiro (PSB), não conseguiram se reeleger, respectivamente, em Porto Alegre, Rio de Janeiro e Rio Branco. A taxa de reeleição foi de $76 \%$, valor semelhante ao observado por Barreto (2009).

Em outras 10 capitais, o prefeito em exercício indicou sucessor. Foram considerados três critérios para se considerar candidato apoiado pelo prefeito (sucessor): (i) o candidato ser filiado ao partido do prefeito (Boa Vista, Fortaleza, Goiânia, João Pessoa, Recife, Salvador, Teresina e Vitória); (ii) candidato ser filiado a um partido pertencente a coligação a que o partido do prefeito faz parte (Belém e Manaus); e (iii) na ausência das duas condições anteriores, o prefeito em exercício declarar publicamente apoio a um candidato (Maceió). Em quatro casos o candidato apoiado pelo mandatário foi eleito. Foram os casos de Boa Vista, Fortaleza, Recife e Salvador. Os casos de insucesso foram observados nas capitais de Belém, João Pessoa, Maceió, Manaus, Teresina e Vitória.

Em São Luís, o prefeito Edivaldo Holanda Júnior, do Partido Democrático Trabalhista (PDT), não se envolveu na disputa. Caso semelhante ocorreu em Goiânia. O primeiro caso foi considerado como fracasso e o segundo como sucesso. A justificativa para tal classificação é a permanência do MDB na governança da capital de Goiás e a alternância ideológica na capital do Maranhão.

A partir dos critérios elencados acima, observamos 15 casos de sucesso eleitoral (ver Tabela 5). 
Tabela 5 - Resultado de interesse e sucesso eleitoral, Brasil, 2020

\begin{tabular}{|c|c|c|c|c|}
\hline Capital & $\begin{array}{l}\text { Prefeito em } \\
\text { exercício }\end{array}$ & Situação & Sucesso & Outcome \\
\hline Aracaju & Edvaldo Nogueira & Reeleição & SIM & 1 \\
\hline Belém & Zenaldo Coutinho & Sucessor & NÃO & 0 \\
\hline Belo Horizonte & Alexandre Kalil & Reeleição & SIM & 1 \\
\hline Boa Vista & Teresa Surita & Sucessor & SIM & 1 \\
\hline Campo Grande & Marquinhos Trad & Reeleição & SIM & 1 \\
\hline Cuiabá & Emanuel Pinheiro & Reeleição & SIM & 1 \\
\hline Curitiba & Rafael Greca & Reeleição & SIM & 1 \\
\hline Florianópolis & Gean Loureiro & Reeleição & SIM & 1 \\
\hline Fortaleza & Roberto Cláudio & Sucessor & SIM & 1 \\
\hline Goiânia & Iris Rezende & Sucessor* & $\mathrm{SIM}^{*}$ & 1 \\
\hline João Pessoa & Luciano Cartaxo & Sucessor & NÃO & 0 \\
\hline Maceió & Rui Palmeira & Sucessor & NÃO & 0 \\
\hline Manaus & Arthur Neto & Sucessor & NÃO & 0 \\
\hline Natal & Álvaro Dias & Reeleição & SIM & 1 \\
\hline Palmas & Cinthia Ribeiro & Reeleição & SIM & 1 \\
\hline Porto Alegre & $\begin{array}{c}\text { Nélson Marchezan } \\
\text { Júnior }\end{array}$ & Reeleição & NÃO & 0 \\
\hline Porto Velho & Hildon Chaves & Reeleição & SIM & 1 \\
\hline Recife & Geraldo Júlio & Sucessor & SIM & 1 \\
\hline Rio Branco & Socorro Neri & Reeleição & NÃO & 0 \\
\hline Rio de Janeiro & Marcelo Crivella & Reeleição & NÃO & 0 \\
\hline Salvador & ACM Neto & Sucessor & SIM & 1 \\
\hline São Luís & $\begin{array}{c}\text { Edivaldo Holanda } \\
\text { Júnior }\end{array}$ & Não se envolveu** & NÃO* & 0 \\
\hline São Paulo & Bruno Covas & Reeleição & SIM & 1 \\
\hline Teresina & Firmino Filho & Sucessor & NÃO & 0 \\
\hline Vitória & Luciano Rezende & Sucessor & NÃO & 0 \\
\hline
\end{tabular}

Fonte: elaboração própria a partir do Tribunal Superior Eleitoral.

Nota: $\left(^{*}\right)$ não se envolveu na disputa, mas o partido disputou a eleição. $\left.{ }^{\star \star}\right)$ não se envolveu na disputa e o partido não lançou candidato a prefeito. 


\section{Análise}

Considerou-se, para a análise, o pressuposto metodológico de que as capitais possuem aspectos contextuais específicos e particulares, capazes de levar a diferentes formas de interação entre as condições, resultando em configurações que podem gerar diferentes resultados a depender do contexto. Por isso, buscou-se compreender, dentro das configurações possíveis, qual ou quais são as possíveis condições necessárias para se explicar a vitória de prefeitos nas capitais brasileiras em 2020 em um contexto nacional muito particular historicamente - o da pandemia de covid-19 - que afetou estruturalmente as dinâmicas políticas locais no país.

Para tanto, utilizamos quatro condições: a aprovação do prefeito $(\mathrm{cl})$; o grau de rigidez das medidas de distanciamento social (c2); a taxa de óbitos (c3); e o alinhamento do prefeito com o presidente (c4). O resultado ou outcome (o) a ser compreendido é o sucesso eleitoral dos prefeitos nas capitais, seja se reelegendo seja fazendo o sucessor.

Para analisarmos, utilizamos a Análise Comparativa Qualitativa, conhecida como QCA (Qualitative Comparative Analysis) e selecionamos a análise multi-value. As condições c2 e c3 admitem três valores ( 0,1 ou 2), tendo um valor intermediário, representado pelo número 1 . Já as condições $\mathrm{cl}, \mathrm{c} 4 \mathrm{e}$ o outcome permitem somente dois valores, 0 ou 1, representando, respectivamente, a ausência e presença da condição.

Primeiramente, apresentamos os resultados da QCA, empregando as quatro condições causais da análise em relação ao outcome. Os testes foram realizados por meio do software Tosmana, versão 1.6.1.0 (ver Quadro 1).

Quadro 1 - Resultados do teste utilizando mv-QCA

\begin{tabular}{|cc|}
\hline Resultados - Solução & Casos (cobertos pela solução) \\
\hline $\mathrm{C} 1\{1\}{ }^{*} \mathrm{C} 3\{0\}{ }^{*} \mathrm{C} 4\{0\}$ & (Belo Horizonte, Campo Grande, Palmas, Curitiba, Florianópolis) \\
+ & (Cuiabá, Fortaleza, Curitiba, Florianópolis, Goiânia, Natal) \\
$\mathrm{C} 1\{1\}{ }^{*} \mathrm{C} 2\{0\}{ }^{*} \mathrm{C} 4\{0\}$ & \\
+ & (Aracaju, Boa Vista, Salvador, São Paulo) \\
$\mathrm{C} 1\{1\}{ }^{*} \mathrm{C} 2\{1\}{ }^{*} \mathrm{C} 3\{1\}{ }^{*} \mathrm{C} 4\{0\}$ & \\
+ & (Porto Velho) \\
\end{tabular}

Fonte: elaboração própria. 
Os resultados das configurações mais relevantes para explicar o sucesso eleitoral do prefeito (seja se reelegendo seja fazendo o sucessor) indicam que quatro configurações são relevantes para a análise dos casos de sucesso eleitoral. Destacamos que há uma condição necessária para explicar o sucesso eleitoral da situação: o não alinhamento do prefeito ao presidente da República (condição 4, com o valor “0”). Essa condição se mostra importante, no entanto, possui pouca variação entre os casos, dado que apenas um prefeito de uma capital (o do Rio de Janeiro) se alinhou ao presidente da República em relação ao combate à pandemia. Os demais buscaram se afastar da retórica bolsonarista e impuseram medidas de isolamento social, em maior ou menor grau. A maior parte dos prefeitos de capitais, portanto, buscou se desvincular do presidente, como forma de se contrapor ao posicionamento negacionista e anticientífico preconizado por Jair Bolsonaro.

Assim, é possível que os prefeitos de capitais, mesmo os mais próximos ideologicamente ao presidente, avaliaram os custos políticos e de saúde pública de negar enfrentar a pandemia de covid-19 com posicionamentos públicos e medidas restritivas, uma vez que são os municípios que sofrem pressões sobre o seu sistema de saúde, além, é claro, das possíveis consequências eleitorais que a ausência de um combate efetivo poderia gerar, sobretudo em um ano de pleitos municipais.

Outra condição relevante da análise, reportada pelo teste, foi a condição "aprovação do prefeito", que se mostrou suficiente para explicar os casos de sucesso eleitoral da situação, ou seja, quando acontece, o resultado é, necessariamente, sucesso. A condição do prefeito ser aprovado pela população ocorre em todas as configurações causais relevantes, o que implica a importância de se considerar a aprovação dos prefeitos na reeleição ou na eleição do sucessor.

Mais uma condição significativa para o sucesso eleitoral da situação é a baixa taxa de mortes por covid-19 (condição 3, com valor “0”), que aparece em cinco capitais. A aprovação do prefeito pode ter sido afetada pela percepção de um bom desempenho do prefeito no combate à pandemia de covid-19. Observamos que todos os casos que apresentaram baixa taxa de mortes são de prefeitos com alta aprovação, sendo esses de sucesso eleitoral. Essas condições, conjuntamente, aparecem em 1/3 dos casos de sucesso: Belo Horizonte, Campo Grande, Curitiba, Florianópolis e Palmas. 
Por fim, diferentemente do esperado, medidas muito rígidas de isolamento social (condição 2, com valor "2") não resultaram, necessariamente, em sucesso eleitoral, pois em apenas dois casos (Belo Horizonte e Porto Velho) essa condição estava presente. Nesse sentido, é possível conjecturar que medidas de isolamento social, que perduram no tempo, podem impactar negativamente a avaliação do prefeito, suscitando consequências sobre os resultados eleitorais, sobretudo, no caso brasileiro, em que essas medidas, por si só, não geram necessariamente um resultado exitoso no combate à pandemia e às suas consequências sociais e econômicas. Lembramos ainda que a intermitência da política pública de auxílio emergencial e a adoção de valores baixos podem ter levado a população a não respeitar as diretrizes de isolamento social, dado que o impacto econômico da paralisação de atividades foi sentido fortemente pelos cidadãos, como se observa no aumento das taxas de pobreza e extrema pobreza, citado anteriormente neste artigo.

Nesse sentido, confirmamos, parcialmente, a nossa hipótese de que a condição "aprovação do prefeito" somada à condição "taxa de mortes baixa" (reflexo de medidas no combate à pandemia) e o "não alinhamento do prefeito ao presidente da República” levam a um resultado exitoso nas eleições. Assim sendo, podemos afirmar que as eleições municipais de 2020 nas capitais brasileiras foram influenciadas por condições políticas e de gestão da saúde. Isso é reforçado nos casos em que, mesmo apresentando taxas de mortes elevadas (condição 3, com o valor “2"), o prefeito se negou ao alinhamento com o presidente da República em termos políticos e de gestão da pandemia, como verificamos nos casos de Cuiabá, Fortaleza, Recife e Porto Velho (ver Tabela 6).

Atesta-se, na Tabela 6, que houve uma configuração que resultou em contradição, isto é, quando uma mesma configuração apresenta dois resultados diferentes. Trata-se dos casos de Belém e Recife. Era esperado que o caso de Belém, com baixa aprovação do prefeito (condição 1, com o valor "0") e alta taxa de mortes (condição 3, com o valor "2"), resultasse em derrota para a situação. A contradição, portanto, reside no caso de Recife, que, com a mesma combinação de condições de Belém, resultou na vitória do sucessor do prefeito. Tal cenário decorre das particularidades da política local da capital pernambucana, em que o resultado de interesse pode ter sido explicado por uma outra configuração. Recife foi o único caso de vitória da situação em que o prefeito não possuía alta aprovação. 
Tabela 6 - Tabela-verdade com as configurações de condições e o outcome - mv-QCA

\begin{tabular}{|c|c|c|c|c|c|}
\hline $\begin{array}{c}\text { C1 } \\
\text { Aprovação } \\
\text { do prefeito }\end{array}$ & $\begin{array}{c}\text { C2 } \\
\text { Rigidez } \\
\text { das } \\
\text { medidas }\end{array}$ & $\begin{array}{c}\text { C3 } \\
\text { Taxa } \\
\text { de } \\
\text { mortes }\end{array}$ & $\begin{array}{c}\text { C4 } \\
\text { Alinhamento } \\
\text { com o } \\
\text { presidente }\end{array}$ & $\begin{array}{l}\text { Outcome } \\
\text { Sucesso } \\
\text { eleitoral }\end{array}$ & Casos \\
\hline 0 & 0 & 1 & 0 & 0 & Rio Branco, São Luís \\
\hline 0 & 1 & 1 & 0 & 0 & Maceió, Manaus, Vitória \\
\hline 0 & 1 & 2 & 0 & $\mathrm{C}^{*}$ & Belém (0), Recife (1) \\
\hline 0 & 2 & 1 & 0 & 0 & João Pessoa, Porto Alegre, Teresina \\
\hline 0 & 2 & 2 & 1 & 0 & Rio de Janeiro \\
\hline 1 & 0 & 0 & 0 & 1 & Curitiba, Florianópolis \\
\hline 1 & 0 & 1 & 0 & 1 & Goiânia, Natal \\
\hline 1 & 0 & 2 & 0 & 1 & Cuiabá, Fortaleza \\
\hline 1 & 1 & 0 & 0 & 1 & Campo Grande, Palmas \\
\hline 1 & 1 & 1 & 0 & 1 & Aracaju, Boa Vista, Salvador, São Paulo \\
\hline 1 & 2 & 0 & 0 & 1 & Belo Horizonte \\
\hline 1 & 2 & 2 & 0 & 1 & Porto Velho \\
\hline
\end{tabular}

Fonte: elaboração própria.

Nota: Macapá foi excluído pelo fato de ter realizado eleições posteriormente à data de elaboração do artigo.

$\left(^{*}\right)$ O "C" representa uma contradição, isto é, uma mesma configuração causal apresenta dois resultados distintos.

Assim como em outras capitais, em que os prefeitos não se alinharam ao presidente da República, essa condição em Recife ganhou uma outra conotação, já que existe um contexto local de forte oposição ao governo federal. Segundo pesquisa do Ibope, realizada entre os dias 16 e 18 de novembro de 2020, o presidente Jair Bolsonaro foi avaliado como ruim e péssimo por $52 \%$ dos entrevistados de Recife ${ }^{16}$. Com isso, abriu-se um espaço político para candidaturas do campo da esquerda: João Campos (PSB) e Marília Arraes (PT), respectivamente bisneto e neta de Miguel Arraes, liderança política histórica do estado de Pernambuco. Campos disputou o segundo turno contra sua prima e sagrou-se vitorioso. Considerando essas particularidades locais, o prefeito recifense, com baixa aprovação, conseguiu eleger seu sucessor.

Em suma, nos resultados encontrados, verificamos que os casos em que a condição 3, taxa de mortes, é zero (o patamar mais baixo de mortos entre todos os casos), todos os prefeitos candidatos à reeleição foram eleitos. Assim sendo, podemos afirmar que ter uma taxa baixa de óbitos por covid-19 constitui

16 Disponível em: https://g1.globo.com/pe/pernambuco/eleicoes/2020/noticia/2020/11/19/ibope-no-recife-vejaavaliacao-de-geraldo-julio-paulo-camara-e-bolsonaro.ghtml. Acesso em: 12 maio 2021. 
condição importante para explicar o sucesso eleitoral, combinado com alta aprovação e não alinhamento do prefeito ao presidente da República. Ou seja, eleitores compensaram a situação quando ela foi muito bem-sucedida nos resultados (baixa taxa de óbitos por covid-19), independentemente das estratégias políticas utilizadas pelos prefeitos (variação na condição 2 - rigidez das medidas). Para exemplificar, tomemos Belo Horizonte, Curitiba e Florianópolis.

No caso de Belo Horizonte, a administração de Alexandre Kalil do Partido Social Democrático (PSD) foi a única que se enquadrou completamente dentro da hipótese esperada. Adotou medidas rígidas de controle e isolamento social, era bem avaliado e não se alinhou ao presidente Bolsonaro, obtendo resultado exitoso em termos de taxa de mortes. Já os prefeitos de Curitiba e de Florianópolis, respectivamente, Rafael Greca e Gean Loureiro (ambos do DEM), não adotaram medidas rígidas de isolamento social por um longo período de tempo, contudo eram aprovados pela população. Assim, apesar da diferença em relação à rigidez das medidas de isolamento no momento inicial da pandemia de covid-19 no Brasil, os prefeitos dessas capitais foram reeleitos.

Por fim, é válido ressaltar que uma estratégia padrão foi adotada por quase todos os prefeitos de capitais: o não alinhamento ao presidente da República. Em um contexto de perda de popularidade de Jair Bolsonaro nas capitais, em função da descoordenação das ações de enfrentamento à pandemia e de sua retórica negacionista, a maior parte dos prefeitos das capitais brasileiras buscou se descolar do presidente, ainda que tenha havido muita variação no grau de restrição das medidas de isolamento adotadas pelos prefeitos nos primeiros meses de pandemia no Brasil.

\section{Considerações finais}

Quando a covid-19 chega ao Brasil já era sabido que as medidas de isolamento e distanciamento social, do mesmo modo como a restrição de circulação de cidadãos (lockdown), apresentavam-se como essenciais no combate à disseminação da doença. A política de testagem em massa da população, assim como o manejo dos doentes e o rastreamento eram ações importantes. Nenhuma dessas políticas foram implementadas no Brasil, por parte do governo federal. Coube aos governadores e prefeitos organizarem e definirem as 
medidas para o enfrentamento à doença, conforme demonstramos neste artigo, arcando com os custos elevados de iniciativas impopulares.

Esse cenário é difícil para qualquer governante, e alguns destes foram submetidos ao teste das urnas no ano de 2020 no Brasil. As eleições municipais transcorreram nesse contexto, tanto que o tema da pandemia marcou muito os debates. Desse modo, este artigo teve como objetivo verificar se, e como, esse cenário pode ter afetado os resultados eleitorais. $\mathrm{O}$ intuito foi observar se os prefeitos candidatos à reeleição e/ou candidatos à sucessão indicados pelo prefeito em exercício nas capitais obtiveram sucesso eleitoral, considerando medidas relacionadas ao combate da covid-19. Para isso, utilizou-se a técnica de análise QCA e foram mobilizadas condições causais políticas e relacionadas à gestão da saúde pública.

Foram quatro as condições analisadas que protagonizaram o modelo aqui empregado. A primeira condição relacionada à adoção de medidas de saúde pública é um indicador que mensura a rigidez das medidas de distanciamento social adotadas nas capitais ao longo dos primeiros meses de pandemia de covid-19 no Brasil. A segunda é a taxa de óbitos decorrentes da doença por 100 mil habitantes. Já as condições de caráter político foram: a aprovação do prefeito e o alinhamento ou não dos prefeitos das capitais ao presidente da República.

De saída podemos conjecturar os efeitos isolados das condições causais. Dessa forma, medidas rígidas de isolamento podem ser bem ou mal avaliadas a depender de fatores tais como sucesso em manter em números baixos a taxa de óbito ou de se evitar o colapso do sistema de saúde. Por outro lado, as consequências econômicas são graves (aumento do desemprego e da informalidade, queda de renda da população) e o prolongamento do fechamento das atividades comerciais pode gerar insatisfação repercutindo negativamente na avaliação dos governantes. Esperamos que nas localidades onde as taxas de óbitos tenham sido menores os prefeitos em situação de disputa de reeleição, ou os seus indicados à sucessão, obtenham sucesso, o que se verificou em $1 / 3$ dos casos exitosos.

Contudo, o interessante do modelo QCA é a análise combinada desses fatores causais para se produzir o resultado de interesse. Por isso, observou-se que a condição baixa taxa de óbitos também é encontrada em casos com alta aprovação do prefeito. No entanto, $2 / 3$ dos casos não foram extremamente 
bem sucedidos quanto à taxa de mortalidade por covid-19. Isso quer dizer que outras condições se combinaram à alta aprovação nessas capitais (suficiente para explicar os casos de sucesso). Recife, no entanto, apresentou uma combinação diferente do esperado, em que o prefeito possuía baixa aprovação e o município contou com alta taxa de mortes por covid-19. Ainda assim, o candidato apoiado pelo prefeito foi eleito.

A QCA permite, diferentemente de outros testes estatísticos, testar teorias e modelos, sem perder de vista as particularidade dos casos, pois, apesar de a pandemia de covid-19 afetar todas as capitais brasileiras, é preciso levar em conta que cada contexto local possui particularidades a serem levadas em conta para a análise do relacionamento existente entre as condições para a compreensão do fenômeno estudado. Outros tipos de teste estatístico (que consideram a independência das variáveis e o efeito das causas sobre o outcome) poderiam perder de vista a natureza interativa das condições e a complexidade causal envolta no problema abordado pelo artigo.

Das 25 capitais consideradas em 15, observou-se o resultado de interesse, ou seja, o prefeito conseguiu se reeleger ou elegeu seu sucessor. O modelo apresentou uma condição causal necessária e uma suficiente, respectivamente o alinhamento do prefeito ao presidente da República e a aprovação do prefeito. Além disso, verificou-se a relevância da taxa de óbitos baixa para o sucesso eleitoral, bem como se evidenciou que a adoção de medidas rígidas de isolamento social, por parte dos prefeitos, não necessariamente leva ao sucesso eleitoral da situação, pois depende de outras combinações de condições que podem levar ao bom desempenho do prefeito e de seu grupo político.

$\mathrm{O}$ artigo, portanto, traz questões importantes sobre a dinâmica política específica em que transcorreram as eleições, incorporando condições relativas à pandemia. De forma comparativa, focando em capitais, o estudo demonstra que o peso do desempenho no combate à pandemia foi relativo e tendeu a beneficiar aqueles muito bem-sucedidos. Desse modo, as condições políticas e de gestão da saúde pública foram relevantes, conjuntamente, para as eleições nas capitais brasileiras em 2020 . 


\section{Referências}

ABRUCIO, Fernando Luiz. Reforma do Estado no federalismo brasileiro: a situação das administrações públicas estaduais. Revista de Administração Pública, Rio de Janeiro, v. 39, n. 2, p. 401-422, jan. 2005.

AJZENMAN, Nicolas; CAVALCANTI, Tiago; DA MATA, Daniel. More than words: leaders' speech and risky behavior during a pandemic. [S. n., S. l.], p. 1-54, 2020. Disponível em: https://ssrn.com/abstract=3582908. Acesso em: 20 maio 2021.

AQUINO, Estela M. L. et al. Medidas de distanciamento social no controle da pandemia de COVID-19: potenciais impactos e desafios no Brasil. Ciência \& Saúde Coletiva, Rio de Janeiro, v. 25, supl. 1, p. 2423-2446, jun. 2020.

ARRETCHE. Marta. Federalismo e políticas sociais no Brasil: problemas de coordenação e autonomia. São Paulo em Perspectiva, São Paulo, v. 18, n. 2, p. 17-26, 2004.

BATISTA, Mariana. Pandemia, política e políticas públicas: a atuação de governadores e prefeitos no enfrentamento da Covid-19. Cadernos Adenauer, Rio de Janeiro, ano XXI, n. 4 (Participação e instituições democráticas no combate à pandemia), p. 51-76, 2020.

BARRETO, Álvaro Augusto de Borba. Reeleição para o Executivo municipal no Brasil (2000-2008). Revista Debates, Porto Alegre, v. 3, n. 2, p. 97-115, jul./dez. 2009.

BORBA, Felipe; CERVI, Emerson Urizzi. Relação entre propaganda, dinheiro e avaliação de governo no desempenho de candidatos em eleições majoritárias no Brasil. Opinião Pública, Campinas, v. 23, n. 3, p. 754.785, set./dez. 2017.

BRAMBOR, Thomas; CENEVIVA, Ricardo. Reeleição e continuísmo nos municípios brasileiros. Novos Estudos - CEBRAP, São Paulo, n. 93, p. 9-21, jul. 2012.

BOL, Damien; GIANI, Marco; BLAIS, André; LOEWEN, Peter John. The effect of COVID-19 lockdowns on political support: some good news for democracy? European Journal of Political Research, [Online], v. 60, n. 2, p. 497-505, May 2021.

CABRAL, Sandro; ITO, Nobuiuki; PONGELUPPE, Leandro. The disastrous effects of leaders in denial: evidence from the COVID-19 crisis in Brazil. [S. 
n., s. l.], p. 1-32, 2021. Disponível em: https://ssrn.com/abstract=3836147. Acesso em: 28 abr. 2021.

CAMARGO JR., Kenneth Rochel de; COELI, Claudia Medina. A difícil tarefa de informar em meio a uma pandemia. Physis - Revista de Saúde Coletiva, Rio de Janeiro, v. 30, n. 2, e300203, p. 1-5, 2020.

CAPONI, Sandra. Covid-19 no Brasil: entre o negacionismo e a razão neoliberal. Estudos Avançados, São Paulo, v. 34, n. 99, p. 209-224, out. 2020.

CODATO, Adriano; CERVI, Emerson; PERISSINOTTO, Renato. Quem se elege prefeito no Brasil? Condicionantes do sucesso eleitoral em 2012. Cadernos Adenauer, Rio de Janeiro, ano XIV, n. 2 (Candidatos, partidos e coligações nas eleições municipais de 2012), p. 61-84, 2013.

DOWNS, Anthony. Uma teoria econômica da democracia. 1. reimpressão. São Paulo: Edusp, 2013.

FERNANDEZ, Michelle; FERNANDES, Luiza da Matta Machado. Atenção primária à saúde no contexto municipal brasileiro e a crise da COVID-19. Boletim Os Governos municipais frente ao Coronavírus do Núcleo de Estudos sobre Política Local (NEPOL), [Online], 8 set. 2020. Disponível em: https://nepoluff.wordpress.com/2020/09/08/atencao-primaria-a-saude-no-contexto-municipal-brasileiro-e-a-crise-da-covid-19/. Acesso em: 21 dez. 2020.

FIGUEIREDO, Marcus. A decisão do voto: democracia e racionalidade. São Paulo: Sumaré/ANPOCS, 1991.

FIOCRUZ - Fundação Oswaldo Cruz. Boletim Extraordinário do Observatório Covid-19. Rio de Janeiro: Fiocruz, 23 mar. 2021. Disponível em: https:// portal.fiocruz.br/sites/portal.fiocruz.br/files/documentos/boletim_extraordinario_2021-marco-23-red-red.pdf. Acesso em: 10 maio 2021.

GIOMMONI, Tommaso; LOUMEAU, Gabriel. Lockdown and voting behaviour: a natural experiment on postponed elections during the COVID-19 pandemic. [S. n., s. l.], p. 1-31, 2020. Disponível em: https://papers.ssrn. com/sol3/papers.cfm?abstract_id=3659856. Acesso em: 24 jul. 2020.

GRIN, Eduardo José. Capacidades estatales en salud: ¿cómo les está yendo a los municipios brasileños en el combate al COVID-19? In: CONGRESO INTERNACIONAL DEL CLAD SOBRE LA REFORMA DEL ESTADO Y DE LA ADMINISTRACIÓN PÚBLICA, 25., 24-27 nov. 2020, Lisboa. Anais 
[...]. Lisboa: Centro Latinoamericano de Administración para El Desarrollo, 2020. p. 1-8. Disponível em: https://clad.org/wp-content/uploads/2020/12/ Informe-de-relatoria-Area-3.pdf. Acesso em: 20 dez. 2020.

MARENCO, André; TEN CATE, Lídia. Votos, partidos e pandemia: o que os resultados de 2020 projetam para o futuro? Cadernos Adenauer, Rio de Janeiro, ano XXII, n. 1 (Impactos das eleições 2020 e da pandemia no Brasil), p. 25-38, 2021.

MENDES, Marcos; ROCHA, C. Alexandre A. O que reelege um prefeito? Brasília: Coordenação de Estudos; Consultoria Legislativa do Senado Federal, 2004. (Textos para discussão n. 7).

MORAES, Rodrigo Fracalossi de. Medidas legais de incentivo ao distanciamento social: comparação das políticas e governos estaduais e prefeituras das capitais no Brasil. Brasília: Dinte/Ipea, 13 abr. 2020. (Nota técnica n. 16). Disponível em: https://www.ipea.gov.br/portal/images/stories/PDFs/ nota_tecnica/200415_dinte_n_16.pdf. Acesso em: 10 dez. 2020.

NASSIF-PIRES, Luiza; CARDOSO, Luísa; OLIVEIRA, Ana Luíza Matos de. Gênero e raça em evidência durante a pandemia no Brasil: o impacto do auxílio emergencial na pobreza e extrema pobreza. São Paulo: Made/FEA/ USP, 22 abr. 2021. (Nota de política econômica n. 010). Disponível em: https://madeusp.com.br/wp-content/uploads/2021/04/NPE-010-VF.pdf. Acesso em: 2 maio 2021.

NUNES, Matheus; AGUILLAR, Arthur; LOTTA, Gabriela; THAMI, Helyn. Do combate à convivência: respostas de municípios à pandemia de COVID-19. São Paulo: IEPS, dez. 2020. (Nota técnica n. 15). Disponível em: https:// ieps.org.br/wp-content/uploads/2020/12/IEPS_NT15.pdf. Acesso em: 22 dez. 2020.

O ESTADO DE SÃO PAULO. 'Maricas', 'histeria', 'não sou coveiro': relembre frases de Bolsonaro sobre a covid-19. O Estado de S. Paulo, [Online], 11 nov. 2020. Disponível em:

https://saude.estadao.com.br/noticias/geral,maricas-histeria-nao-sou-coveiro-relembre-frases-de-bolsonaro-sobre-a-covid-19,70003509925. Acesso em: 15 dez. 2020.

PEREIRA, Carlos; MEDEIROS, Amanda; BERTHOLINI, Frederico. O medo da morte flexibiliza perdas e aproxima polos: consequências políticas da 
pandemia da COVID-19 no Brasil. Revista de Administração Pública, Rio de Janeiro, v. 54, n. 4, p. 952-968, jul./ago. 2020.

PÉREZ-LIÑAN, Aníbal. El método comparativo y el análisis de configuraciones causales. Revista Latinoamericana de Política Comparada. Quito, v. 3, p. 125-148, jan. 2010.

PESSOA JR., José Raulino Chaves; RUBIATTI, Bruno de Castro. Política pública em desalinho: (des)coordenação federal no combate à Covid-19. In: FROTA, Francisco; FROTA, Maria Helena; SILVA, Maria Andréa. O impacto da Covid-19 nas políticas públicas. Fortaleza: Edmeta Editora, 2020. p. 99-122. Disponível em: https://storage.woese.com/documents/88ba515bf0e412e771d2e03307a213a70230590d.pdf. Acesso em: 19 nov. 2020. RAGIN, Charles C. Fuzzy set social science. Chicago: University of Chicago Press, 2000.

RAGIN, Charles C. The comparative method: moving beyond qualitative and quantitative strategies. Berkeley: University of California Press, 1987. RIBEIRO, José Mendes; RASGA, Marcelo; OUVERNEY, Assis Mafort; PINTO, Luiz Felipe; SILVA, Cosme Marcelo F. P. da. Federalismo e políticas de saúde no Brasil: características institucionais e desigualdades regionais. Ciência \& Saúde Coletiva, Rio de Janeiro, v. 23, n. 6, p. 1777-1789, jun. 2018. RIHOUX, Benoit; RAGIN, Charles C. Configurational comparative methods: qualitative comparative analysis (QCA) and related techniques. Thousand Oaks: Sage Publications, 2009.

ROCHA, Marta Mendes da. Os governos municipais frente ao Coronavírus. In: GROSSI, Miriam Pillar; TONIOL, Rodrigo (org.). Cientistas sociais e o coronavírus. São Paulo: ANPOCS; Florianópolis: Tribo da Ilha, 2020a. cap. 39, p. 196-199. Disponível em: http://anpocs.com/images/stories/boletim/ boletim_CS/livro_corona/Ebook_Cientistas_Sociais_Coronav\%C3\%ADrus_ baixa.pdf. Acesso em: 20 ago. 2021.

ROCHA, Marta Mendes da et al. Boletim Os Governos municipais frente ao Coronavírus. [Online]: NEPOL/UFJF, 2020b. Disponível em: https://nepoluff.wordpress.com/os-governos-municipais-frente-ao-coronavirus/. Acesso em: $1^{\circ}$ maio 2020.

ROCHA, Marta Mendes da; ALMEIDA, Paula Emília Gomes de; CORRÊA, Izabela. Os governos municipais frente ao coronavírus: um balanço 
provisório. Boletim Os Governos municipais frente ao Coronavírus do Núcleo de Estudos sobre Política Local (NEPOL), [Online], 28 abr. 2020. Disponível em: https://nepoluffffiles.wordpress.com/2020/04/primeiro-relatc3b3rio-nepol-ufff_28abril2020.pdf. Acesso em: 21 dez. 2020.

ROCHA, Marta Mendes da; KERBAUY, Maria Teresa Miceli. Poder local e representação política nos municípios brasileiros: contribuições para uma agenda de pesquisas. In: ROCHA, Marta Mendes da; KERBAUY, Maria Teresa Miceli (org.). Eleições, partidos e representação política nos municípios brasileiros. Juiz de Fora: Editora UFJF, 2014. cap. 1, p. 17-34.

RÔMULO, H.; MARQUES, A; FERNANDEZ, M.; ALMEIDA, H; SILAME, T. Pacto federativo e coordenação intergovernamental na saúde em tempos de COVID-19. In: SANTANA, Luciana; NASCIMENTO, Emerson. Governos e o enfrentamento da COVID-19. Maceió: EDUFAL, 2021. cap. 3, p. 26-42. No prelo.

SANDES-FREITAS, Vitor Eduardo Veras de; BIZZARRO-NETO, Fernando. Qualitative Comparative Analysis (QCA): usos e aplicações do método. Revista Política Hoje, Recife, v. 24, n. 2, p. 103-118, jan. 2016.

SANTANA, Luciana (org.). Os governos estaduais e as ações de enfrentamento à pandemia no Brasil: II Série especial $\mathrm{ABCP}$. Rio de Janeiro: $\mathrm{ABCP}$, 8-12 jun. 2020a. Disponível em: https://cienciapolitica.org.br/web/noticias/2020/06/especial-abcp-governos-estaduais-e-acoes-enfrentamento. Acesso em: 6 jul. 2021

SANTANA, Luciana (org.). Os governos estaduais e as ações de enfrentamento à pandemia no Brasil: III Série especial $A B C P$. Rio de Janeiro: $A B C P$, 13-17 jul. 2020b. Disponível em: https://cienciapolitica.org.br/web/noticias/2020/07/especial-abcp-governos-estaduais-e-acoes-enfrentamento. Acesso em: 6 jul. 2021.

SANTANA, Luciana; PEREZ, Olívia Cristina. Os governos estaduais e as ações de enfrentamento à pandemia no Brasil. Jornal Nexo, [Online], 10 maio 2020. Disponível em: https://www.nexojornal.com.br/especial/2020/05/10/Comoos-governos-estaduais-lidam-com-a-pandemia. Acesso em: 29 jul. 2020.

SANTANA, Luciana; PEREZ, Olívia Cristina; NASCIMENTO, Emerson. Pandemia, negacionismo e crise no governo Bolsonaro In: SANTANA, Luciana; NASCIMENTO, Emerson (org.). Governos e o enfrentamento da COVID-19. Maceió: EDUFAL, 2021. cap. 2, p. 7-25. No prelo. 
SANTOS, Manoel Leonardo; PÉREZ-LIÑÁN, Aníbal; GARCÍA MONTERO, Mercedes. El control presidencial de la agenda legislativa en América Latina. Revista de Ciencia Política, Santiago, v. 34, n. 3, p. 511-536, 2014.

SCHAEFER, Bruno Marques; RESENDE, Roberta Carnelos; EPITÁCIO, Sara de Sousa F; ALEIXO, Mariah Torres. Ações governamentais contra o novo coronavírus: evidências dos estados brasileiros. Revista de Administração Pública, Rio de Janeiro, v. 54, n. 5, p. 1429-1445, out. 2020.

SCHNEIDER, Carsten; WAGEMANN, Claudius. Set-theoretic methods for the Social Sciences: a guide for qualitative comparative analyses. Cambridge: Cambridge University Press, 2012.

SOARES, Márcia Miranda; MACHADO, José Ângelo. Federalismo e políticas públicas. Brasília: ENAP, 2018.

SOUZA, Celina. Coordenação de políticas públicas. Brasília: ENAP, 2018. SOUZA, Celina. Democracia, participação social e funcionamento das instituições: situação e perspectivas da federalização do desenvolvimento. Revista de Administração Pública, Rio de Janeiro, v. 26, n. 3, p. 15-35, 1992.

SOUZA, Celina. Federalismo, descentralização e reforma constitucional em contextos de desenvolvimento regional desigual. Organizações \& Sociedade, Salvador, v. 4, n. 9, p. 127-148, maio/ago., 1997.

SOUZA, Celina. Political and financial decentralization in democratic Brazil.

Local Government Studies, London, v. 20, n. 4, p. 588-609, 1994.

VEIGA, Luciana Fernandes; SANTOS, Sandra Avi dos; NEVES, Daniela Silva. Como a avaliação do governo local, a imagem dos candidatos e a configuração da disputa influenciam na reeleição do prefeito: evidências de oito capitais no Brasil, 2008. In: CONGRESSO LATINO AMERICANO DE OPINIÃO PÚBLICA DA WAPOR, 4., 4-6 maio 2011, Belo Horizonte. Anais [...]. Belo Horizonte: World Association for Public Opinion Research, 2011. p. 1-30. Disponível em: http://opiniaopublica.ufmg.br/site/files/biblioteca/ Luciana-Veiga.pdf. Acesso em: 10 nov. 2011

WAGEMANN, Claudius. Qualitative Comparative Analysis (QCA) and fuzzy sets, applications and perspectives for a mixed methods strategy. Estudio/Working Paper de la Universidad Autónoma de Madrid, [Online], n. 142, p. 1-30, 2012. Disponível em: https://www.uam.es/Derecho/documento/1242662857640/ WP_Wagemann.pdf?blobheader=application/pdf. Acesso em: 20 ago. 2021. 


\section{Combate à pandemia de covid-19 e sucesso eleitoral nas capitais brasileiras em 2020}

Resumo: O artigo propõe analisar o sucesso eleitoral de candidatos às prefeituras das capitais brasileiras em 2020. As eleições de 2020 foram realizadas em um contexto de pandemia de covid-19, em que os prefeitos tiveram de adotar medidas para minimizar efeitos da crise de saúde pública. Por isso, buscou-se explicar o sucesso eleitoral por meio de quatro condições básicas: aprovação do prefeito; grau de restrição das medidas de isolamento social; alinhamento do prefeito com o presidente; e taxa de óbitos por covid-19 por 100 mil habitantes. Para testar o modelo, utilizou-se a Qualitative Comparative Analysis (QCA) para compreender as diversas configurações possíveis para se explicar o sucesso eleitoral nas capitais. Encontrou-se que as capitais com prefeitos bem avaliados e baixas taxas de óbitos elegeram candidatos da situação, ainda que outras configurações também tenham levado ao sucesso eleitoral desses candidatos.

Palavras-chave: sucesso eleitoral; covid-19; prefeitos; capitais brasileiras; Qualitative Comparative Analysis.

\section{Confronting the covid-19 pandemic and electoral success in Brazilian state capitals in $\mathbf{2 0 2 0}$}

Abstract: The article proposes to analyze the electoral success of candidates for mayor of Brazilian state capitals in 2020. The 2020 elections were held in the context of the covid-19 pandemic, in which mayors had to take measures to minimize the effects of the public health crisis. We sought to explain electoral success through four basic conditions: the approval of the mayor; the restrictiveness of social isolation measures; the political alignment of the mayor to the president; and the covid-19 death rate per 100 thousand inhabitants. To test the model, we used Qualitative Comparative Analysis (QCA) to understand the different possible configurations that explain the electoral success in the capitals. We found that capital cities with whose mayors had high approval rates and with low death rates elected incumbent candidates, although other configurations also led to the electoral success of these candidates.

Keywords: electoral success; covid-19; mayors; Brazilian state capitals; Qualitative Comparative Analysis. 


\section{La gestión de la pandemia de covid-19 y el éxito electoral en las capitales brasileñas en 2020}

Resumen: El artículo propone analizar el éxito electoral de los candidatos a los ayuntamientos de las capitales brasileñas en 2020. Las elecciones de 2020 se realizaron en un contexto de la pandemia covid-19, en la que alcaldes debieron tomar medidas para minimizar los efectos de la crisis en la salud pública. Por ello, buscamos explicar el éxito electoral a través de cuatro condiciones básicas: la aprobación del alcalde; el grado de restricción de las medidas de aislamiento social; alienación política del alcalde con el presidente; y la tasa de mortalidad por covid-19 por cada 100 mil habitantes. Para probar el modelo, utilizamos el Análisis Cualitativo Comparativo (QCA) para comprender las diferentes configuraciones posibles para explicar el éxito electoral en las capitales. Se constató que las capitales con alcaldes bien evaluados y con bajas tasas de mortalidad por covid-19 eligieron a candidatos ya titulares, aunque otras configuraciones también han propiciado el éxito electoral de estos candidatos.

Palabras clave: Éxito electoral; covid-19; alcaldes; capitales brasileñas; análisis comparativo cualitativo.

Recebido em 24 de dezembro de 2020

Aprovado em 26 de junho de 2021. 